\title{
THE
}

\section{Inbreeding produces trade-offs between maternal fecundity and offspring survival in a monandrous spider}

\author{
Zhanqi Chen \\ Evan L. Preisser \\ University of California - Davis, preisser@uri.edu \\ Rong Xiao \\ Jian Chen \\ Daiqin Li
}

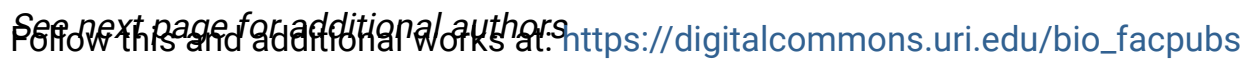

The University of Rhode Island Faculty have made this article openly available.

Please let us know how Open Access to this research benefits you.

This is a pre-publication author manuscript of the final, published article.

Terms of Use

This article is made available under the terms and conditions applicable towards Open Access

Policy Articles, as set forth in our Terms of Use.

\section{Citation/Publisher Attribution}

Chen, Z., Preisser, E. L., Xiao, R., Chen, J., Li, D., \& Jiao, X. (2017). Inbreeding produces trade-offs between maternal fecundity and offspring survival in a monandrous spider. Animal Behaviour, 132, 253-259. doi: 10.1016/j.anbehav.2017.08.020

Available at: https://doi.org/10.1016/j.anbehav.2017.08.020 


\section{Authors}

Zhanqi Chen, Evan L. Preisser, Rong Xiao, Jian Chen, Daiqin Li, and Xiaoguo Jiao 
1 Inbreeding produces trade-offs between maternal fecundity and offspring survival in a

2 monandrous spider

3

4 Zhanqi Chen ${ }^{1}$, Evan L. Preisser ${ }^{2}$, Rong Xiao ${ }^{1}$, Jian Chen ${ }^{1}$, Daiqin $\mathrm{Li}^{3}, \mathrm{Xiaoguo}_{\mathrm{Jiao}}{ }^{*}$

6 1. Center for Behavioral Ecology \& Evolution, Hubei Collaborative Innovation Center for

7 Green Transformation of Bio-Resources, College of Life Sciences, Hubei University, Wuhan

8 430062, China; 2. Biological Sciences Department, University of Rhode Island, Kingston RI

9 02881, USA; 3. Department of Biological Sciences, National University of Singapore, 14

$10 \quad$ Science Drive 4, Singapore 117543)

11

12 *Correspondence: Xiaoguo Jiao

13 College of Life Sciences, Hubei University, Youyi Street 368, Wuchang, Wuhan 430062 ,

14 Hubei, PR China

15 Tel/Fax: +86-27-88661237-8061

16 E-mail: jiaoxg@hubu.edu.cn

17

Word Count: 5,422 words 

related parents, a phenomenon termed inbreeding depression. While many species have been shown to rely on pre- and/or post-copulatory mate choice to avoid inbreeding, such research has focussed largely on polyandrous rather than monandrous species. The absence of postcopulatory mate choice in monandrous species suggests that pre-copulatory mate choice should play a more important role in inbreeding avoidance. We used a monandrous wolf spider, Pardosa astrigera, as a model system to investigate whether (1) male spiders respond differently to sibling and non-sibling females; (2) female spiders respond differently to sibling versus non-sibling males; and (3) inbreeding affects females and their offspring. Male courtship behavior was similar for sibling and non-sibling females; although females were less likely to mate with siblings, over half did mate successfully with their sibs. Siblingmated females produced fewer offspring from the first eggsac and fewer total offspring, but inbred offspring survived longer in a range of environments than their outbred counterparts. This suggests that the fitness costs of reduced fecundity in sibling-mated females may be offset by higher offspring survivorship. Our results highlight the importance of considering both parent and offspring fitness when addressing the costs of inbreeding, and are the first to document the impact of inbreeding on sexual behaviour and reproductive fitness in a monandrous spider.

Keywords: Courtship, fecundity, fitness, inbreeding avoidance, mate discrimination, mating, monandrous, spider 

resulting from increased homozygosity at loci carrying rare deleterious recessive alleles or exhibiting over-dominance (Charlesworth \& Charlesworth, 1987; Lynch, 1991). The fitness costs of inbreeding have been documented in an array of taxa, and exert a strong selective pressure on both mating and reproductive strategies (Bateson, 1982; Escobar et al., 2011;

Muller \& Muller, 2016; Szulkin, Stopher, Pemberton, \& Reid, 2013). The impact of inbreeding on offspring can be altered by the surrounding environment. Varying environmental conditions, for example, can cause stress and often exacerbate the effects of inbreeding (Armbruster \& Reed, 2005). These stressors can include suboptimal diets (Fox \& Reed, 2011; Freitak, Bos, Stucki, \& Sundstrom, 2014) and variation in temperature (Fox \& Reed, 2011; Kristensen, Barker, Pedersen, \& Loeschcke, 2008), and are widely recognized to exacerbate the fitness costs of inbreeding.

An array of mechanisms have evolved for avoiding inbreeding and/or reducing its fitness costs (Firman \& Simmons, 2008; Pusey \& Wolf, 1996; Ruch, Heinrich, Bilde, \& Schneider, 2009). Prior to breeding, sex-biased dispersal from natal habitats decreases inbreeding risk in some species (Keane, 1990; Pusey \& Wolf, 1996; Smith, Su, Berger-Tal, \& Lubin, 2016), while other species prefer to mate with unrelated partners (Fischer, Karl, Heuskin, Janowitz, \& Dotterl, 2015; Thomas \& Simmons, 2011; Whitehorn, Tinsley, \& Goulson, 2009). The recognition and avoidance of related individuals requires chemical or other cues that are indicative of relatedness (Firman \& Simmons, 2008; Pusey \& Wolf, 1996; Ruch et al., 2009). In insects, for instance, both mate recognition and pre-mating preference

61 are affected by cuticular hydrocarbons (CHCs; Geiselhardt, Otte, \& Hilker, 2009; Thomas \& 
Simmons, 2011) and other compounds (Chuine, Sauzet, Debias, \& Desouhant, 2015;

Herzner, Schmitt, Heckel, Schreier, \& Strohm, 2006). The CHC profiles of several chrysomelid beetle species, for example, affect mate choice and facilitate outbred mating (Geiselhardt et al., 2009). Even if inbreeding does occur, its impact in polyandrous species can be reduced via post-copulatory mechanisms in which differential fertilization success species, organisms capable of employing both pre- and post-copulatory mate choice strategies 
Chen, 2008). Olfaction plays a key role in male courtship. Males initiate courtship in response to pheromones associated with female dragline silk, and males can distinguish silk cues from individuals differing in sex and mating status (Xiao et al., 2015). While female $P$. astrigera are monandrous, the polygynous males can copulate with as many as five virgin females at 24h intervals (Jiao et al., 2011; Wu et al., 2008). While inbreeding depression has not previously been addressed in this species, prior research into its courtship and mating behavior make it an ideal model system for addressing such questions.

We report work investigating inbreeding avoidance through courtship behavior and the impact of inbreeding on reproductive output and offspring survival in the monandrous wolf spider $P$. astrigera. We compared male courtship behaviors in response to dragline silk of sibling and non-sibling females to test for male pre-copulatory kin discrimination. We also conducted non-choice mating experiments to compare the likelihood of sibling and nonsibling mating. In addition, we measured post-mating female reproductive output (both number and size of offspring) to determine the cost of inbreeding on female fitness. Finally, we compared the survival of inbred versus outbred offspring across a range of temperatures. We predicted that strong pre-copulatory barriers exist to sibling mating, that these barriers are stronger in females than in males, that inbreeding reduces both maternal and offspring fitness, and that higher temperatures increase the impact of inbreeding on the offspring.

\section{Methods}

Subadult P. astrigera of the overwintering generation were collected in April 2012 from Ma'anshan Forest Park, Wuhan, Hubei Province, China. Spiders were housed individually in opaque Plexiglass enclosures $(5.0 \times 5.0 \times 7.5 \mathrm{~cm}, 1 \times \mathrm{W} \times \mathrm{h})$ at $25 \pm 0.5^{\circ} \mathrm{C}$ with 
$60 \pm 10 \%$ relative humidity ('RH') and on a 14:10 light:dark ('1:d') cycle. Spiders were supplied with water ad libitum and fed every 3 days with a mixture diet of Drosophila melanogaster and mosquitoes (Culicidae). Individuals were checked daily for subadult molting in order to determine the exact date of adulthood. We used randomly-selected adult spiders to create the ten male:female pairs used to generate ten families. Mated females were maintained as above. We randomly selected and reared 30 spiderlings from each eggsac; each spiderling was reared individually in a glass tube $(1.5 \mathrm{~cm}$ diameter $)$. Spiderlings were supplied with water ad libitum and fed every two days with a mixture of $D$. melanogaster and mosquitoes. Once the spiders matured, similarly-sized females in their third day of adulthood were selected for silk collection and/or behavioural trials. All spiders were virgin and used only once; all adult spiders, except for those females whose lifespan was measured (details below) were released following their involvement in the experiment.

\section{Experiment 1: Male response to sibling/nonsibling female silk}

Silk was collected by placing each female in a 9-cm diameter glass petri dish lined with filter paper (15 cm diameter; Double Ring brand, Hangzhou, Zhejiang, China) for $12 \mathrm{~h}$. All females were starved for $12 \mathrm{~h}$ beforehand to reduce faecal contamination. All silk was used within 18-24 h after its collection, a period of time over which silk-borne spider cues do not degrade under natural conditions (Baruffaldi, Costa, Rodriguez, \& Gonzalez, 2010; Costa, Curbelo, \& Perez-Miles, 2015).

We randomly selected similarly-sized virgin males $(N=65,5-7$ individuals per family) aged 5-10 days post-maturation and assigned each to one of the two female silk stimulus treatments. Male body size did not differ significantly between treatments $\left(t_{61}=\right.$ 
$0.75, P=0.45)$. Thirty-three males were exposed to silk from a female in the same family (sibling), and 32 males were exposed to silk from a female from a different family (nonsibling); silk from a given female was only used for one male.

Behavioural trials were carried out in a cylindrical glass container open at both ends (10.5-cm diameter, 12-cm length). After setting the cylindrical glass container on the silkcovered filter paper, a single male was gently introduced onto the stimulus filter paper with a glass tube from above and its courtship behaviour videotaped (HDR-CX580E Sony video camera) for five min. We chose this cut-off period because preliminary experiments revealed that male spiders exposed to silk either began courtship rapidly (within two minutes) or never engaged in courtship behavior (Roberts \& Uetz, 2004). Each arena was cleaned after each trial with $70 \%$ ethanol and left to air dry. Videos were analysed using Observer v. 4.1 (Noldus Information Technology, Wageningen, The Netherlands), a software package for behavioural data analysis. On the basis of work reported in Wu et al. $(2007,2008)$ and Jiao et al. (2009), the following courtship behaviours were analysed: (a) time to the start of body shaking and (b) foreleg raising; (c) The number of body shaking and (d) foreleg raising events per minute. Data from all trials was analysed to determine whether the likelihood of courting behavior was affected by female relatedness. For analysis of specific courtship behaviors, data from trials where such behaviors did not occur within five minutes were excluded from analysis.

\section{Experiment 2: Male and female responses to siblings and non-siblings}

We paired individual virgin females $(N=120 ; 12$ spiders from each family) in their third day of adulthood with individual virgin males 5-10 days into adulthood; 60 male-female 
pairs were siblings, and the other sixty pairs were non-siblings. All spiders belonged to one of the ten families. We recorded behavioural data on male courtship as per experiment \#1, and also whether mating occurred within 30 minutes. Data for replicates in which no mating occurred was used to analyse mating likelihood in treatments but not included in other mating-dependent analyses (described below). Forty-two females mated with non-sibling males and 31 females with sibling males; each mating produced an eggsac. The unit of replication for analysis of mating behavior was individual mating pairs $(N=73)$.

\section{Experiment 3: Impact of inbreeding on female fecundity and offspring survival}

We held mated females individually under the conditions described above, and checked daily for an eggsac. Although all 73 females produced eggsacs, 20 cannibalized their eggsacs prior to hatching; eggsacs from the remaining 53 spiders (26 sibling and 27 nonsibling) hatched successfully. The size (measured as carapace width) of female spiders did not differ between treatments $\left(t_{45}=0.51, P=0.61\right)$. We removed the eggsacs of five randomly-chosen sibling-mated spiders and eight non-sibling-mated spiders for an unrelated experiment, leaving a total of 40 eggsac-producing females (21 sibling and 19 non-sibling, representing all ten families). For each female, we recorded time (days) from mating to first eggsac production and from first eggsac production to hatching. After the first eggsac was produced, each female was kept alive and fed ad libitum until death to measure their lifespan and see if they produced additional eggsacs. Offspring from these eggsacs plus the number of offspring from the first eggsac determined total offspring production per female.

After recording the number of offspring emerging from the first eggsac, we preserved five randomly-selected offspring from it in $70 \%$ alcohol for carapace width measurements. 
were kept in 1.5-cm diameter glass tubes with no water and held at one of three temperatures $\left(15,25\right.$ and $\left.30^{\circ} \mathrm{C}\right)$ without food nor water $(60 \pm 10 \% \mathrm{RH}, 14: 10$ light:dark cycle $)$. These temperatures were chosen to reflect the mean, high, and absolute highest temperatures spiders might experience at this point in the year. While $25^{\circ} \mathrm{C}$ temperatures are ideal for spider development when water is provided ad libitum, in the absence of water such high temperatures speed desiccation and death. Survival was checked twice daily. The survival of all offspring of a female at a given temperature was averaged; the unit of replication was mean offspring survival per female per temperature $(N=120)$.

\section{Ethical note}

Animal care in all experiments complied with the current laws and standards of China (Bayne \& Wang, 2014).

\section{Data analysis}

Data were analyzed by fitting a generalized linear mixed model (glmm) with the appropriate link function (e.g. Gaussian, Poisson, binomial) using penalized quasi-likelihood (PQL) ('glmmPQL' function in MASS package, Venables \& Ripley, 2002) in R (R Development Core Team, 2017). Family nested within treatment (i.e. sibling and non-sibling) was used in all models as a random effect to account for the non-independence of multiple individuals from a given family. A Wald $\chi^{2}$ test was used to extract $\chi^{2}$ and $P$-values on the glmm model using the 'Anova' function in the 'car' package (Fox \& Weisberg, 2011).

Additionally, data on mean offspring size from experiment three was analyzed by including mating treatment in all models as a fixed effect with female carapace width (a proxy for body 
size) as a covariate. Data on mean offspring survival from experiment three was also analyzed as above but with the addition of a fixed main effect (temperature) and a temperature*mating interaction.

\section{Results}

Twenty-one of 33 males responded to sibling silk, and 22 of 32 males responded to non-sibling silk; the proportion of non-responding males did not differ between treatments $\left(\chi^{2}{ }_{1}=0.50, P=0.48\right)$. Males did not differentiate between sibling and non-sibling females when exposed to either silk cues (Fig. 1, top panel) or directly to the females themselves (Fig. 1, bottom panel). The start of courtship behaviors such as foreleg raising or body shaking was unaffected by female relatedness, whether conveyed via silkborne cue (Figs. 1A and 1B, respectively; $\chi^{2}{ }_{1}$, both $P>0.5$ ) or direct female exposure (Figs. 1E and 1F; both $P>0.5$ ). There were also no treatment differences in the frequency of courtship behaviors in both the silk-cue (Figs. 1C and 1D; both $P>0.4$ ) and direct exposure (Figs. 1G and 1H; both $P>0.3$ ) experiments.

Despite similar male courtship behavior, mating occurred more often between unrelated individuals ( $70 \%$ of pairings) than between siblings $\left(52 \% ; \chi^{2}{ }_{1}=4.26, P=0.039\right)$. The time from mating to first eggsac production (Fig. 2A) and from production to hatching (Fig. 2B) was similar for both sibling and non-sibling pairings $\left(\chi^{2}{ }_{1}=0.43\right.$ and 0.31 , respectively, both $P>0.05)$. The fecundity of sibling-mated females, however, was much lower than that of non-sibling mated ones: they produced $41 \%$ fewer offspring in their first eggsac (Fig. $2 \mathrm{C} ; \chi^{2}{ }_{1}=24.8, P<0.001$ ) and $44 \%$ fewer offspring in total (Fig. $2 \mathrm{D} ; \chi^{2}{ }_{1}=34.2$, $P<0.001)$. Five of 27 non-sibling mated females produced a second eggsac, while only two 
of 26 sibling-mated females did so; this difference was not, however, significant $\left(\chi^{2}{ }_{1}=1.40, P\right.$

$217=0.24)$. There were no treatment-level differences in the longevity of mated adult females $218 \quad\left(\chi^{2}{ }_{1}=0.07, P=0.80\right)$. $[\mathrm{SE}]$ and $1.27 \pm 0.007 \mathrm{~mm}$ carapace width, respectively; $\left.\chi^{2}{ }_{1}=1.79, P=0.18\right)$. Offspring in the sibling treatment survived an average of $23 \%$ longer $(9.3 \pm 0.20[\mathrm{SE}]$ and $7.1 \pm 0.13$ days; $\left.\chi^{2}{ }_{1}=33.0, P<0.001\right)$ across all three temperature treatments than those in the non-sibling treatment (Fig. 3). Spiderling survival declined as temperature increased $\left(\chi_{2}^{2}=111, P<\right.$ 0.001 ), and there was a significant mating*temperature interaction $\chi_{2}^{2}=10.3, P=0.006$ ).

This interaction reflected the fact that the survival advantage of inbred offspring generally decreased as temperature increased; inbred offspring survived $28 \%$ longer in the $15^{\circ} \mathrm{C}$ treatment, $19 \%$ longer in $25^{\circ} \mathrm{C}$, and $22 \%$ longer in $30^{\circ} \mathrm{C}$ (Fig. 3 ). unrelated individuals, but over half still mated successfully with male siblings. While weak sibling avoidance suggests a minimal cost to inbreeding, the fecundity of sibling-mated females was reduced (Fig. 2). Experimental assessment of their offspring, however, revealed that although they were the same size as their outbred congeners, the offspring of siblingmated females survived $\sim 20 \%$ longer under a range of environmental conditions (Fig. 3). 
exploring the costs of inbreeding.

The fact that females bred less often with sibling males demonstrates their ability to detect relatedness via chemical or other cues; mate recognition via such cues often plays a key role in inbreeding avoidance (Geiselhardt et al., 2009; Herzner et al., 2006; Lihoreau \& Rivault, 2010; Thomas \& Simmons, 2011). In many spider species, males employ silkmediated cues for species, sex, and mating status recognition (Gaskett, 2007; Xiao et al., 2015). Given this, we were surprised to find no evidence for male pre-copulatory mate choice in response to either females or their silk. This result likely reflects the fact that male $P$. astrigera are polygynous and compete fiercely with each other for mating opportunities (Jiao et al., 2011). Because the males can remate, they have little to lose from inbreeding and should seek to maximize mating opportunities even under strong inbreeding depression (Duthie et al., 2016).

The inbreeding-related decline in female fecundity is consistent with results from a wide range of taxa (Charlesworth \& Charlesworth, 1987; Hedrick \& Garcia-Dorado, 2016; Pusey \& Wolf, 1996). The $>40 \%$ reduction in offspring number is especially harmful in a monandrous species like $P$. astrigera, since females cannot compensate via subsequent matings with higher-quality partners. Given these high costs, it may seem surprising that over half of the females in the sibling group chose to mate. One explanation for this result may involve our decision to employ a no-choice design in our mating assays. A recent metaanalysis (Dougherty \& Shuker, 2015) found stronger mating preferences in choice experiments where females were exposed to different mates. If this is the case in P. astrigera, our results may underestimate the strength of female mate preference. Alternately, sex-biased 
dispersal prior to reproductive maturity has been shown to reduce the likelihood of inbreeding in some species (Keane, 1990; Pusey \& Wolf, 1996; Smith et al., 2016). If such sex-biased dispersal occurs in this species, it may reduce the need for females to strongly discriminate against related individuals. Finally, the weak sibling avoidance we observed may highlight the importance of viewing the costs of inbreeding depression within the larger context of female inclusive fitness - and specifically, the higher survival of inbred offspring. more sensitive to environmental variation than their outbred congeners, presumably because the stress associated with that variation increases the expression of deleterious recessive 
this the case, we might expect offspring size to differ. Although spiderling carapace width was negatively correlated with offspring per eggsac, there were no between-treatment differences. Inbreeding parents may allocate more nutrients to eggs (Wilder, 2011) or employ other forms of investment (e.g., parental care; Pilakouta \& Smiseth, 2016). Future research might address whether such alternate forms of parental provisioning occur in this system. Our results are also consistent with the hypothesis that inbreeding in $P$. astrigera, while harmful to parental fecundity, benefits one or more traits that prolong offspring survival. The effects of inbreeding are often trait-specific, with some traits strongly affected and others remaining similar to those found in outbred congeners (Kristensen et al., 2008; Pilakouta \& Smiseth, 2016; Valtonen, Roff, \& Rantala, 2011). Given this, it is unsurprising that inbreeding can increase the benefit of some life history traits. In the cricket Teleogryllus commodus, for example, inbred individuals exhibit higher macroparasitic immunity than outbred individuals (Gershman et al., 2010). Similarly, male Litoria peronii frogs that mate with sibling females sire more offspring in sperm competition (Sherman, Wapstra, Uller, \& Olsson, 2008). These benefits can also be sex-specific: inbreeding in the beetle Callosobruchus maculatus increases male - but shortens female - lifespan (Bilde, Maklakov, Meisner, la Guardia, \& Friberg, 2009). In our case, an increase in desiccation tolerance or modifications to similar traits might provide inbred spiderlings a survival advantage consistent with our results.

While inbreeding is generally harmful, its costs can vary substantially both between and within species (Aviles \& Bukowski, 2006; Szulkin et al., 2013); theory predicts an optimal balance between inbreeding and outbreeding (Kokko \& Ots, 2006; Puurtinen, 2011; 
Richard, Losdat, Lecomte, de Fraipont, \& Clobert, 2009). Our results reveal unexpectedly weak inbreeding avoidance in a monandrous spider and demonstrate that sibling mating reduces maternal fecundity but increases offspring survival in a range of environmental conditions. These findings highlight the importance of viewing maternal fecundity in the larger context of inclusive fitness; a relatively low degree of inbreeding avoidance may reflect a trade-off between parental and offspring fitness. This is especially important for monandrous organisms that, by definition, cannot employ post-copulatory mechanisms to reduce the impact of inbreeding. In such species, weak sibling avoidance may be indicative of inbreeding-related tradeoffs: future research should explore both the conditions that necessitate pre-copulatory mate choice strategies and determine its strength.

\section{Acknowledgements}

We thank Dr. Shichang Zhang, Dr. Oliver Martin, and two anonymous reviewers for their helpful comments and suggestions on the manuscript, and Dr. Chad Rigsby for his assistance with the statistical analyses. Financial assistance was provided by the National Natural Science Foundation of China (30800121).

\section{References}

Armbruster, P., \& Reed, D. H. (2005). Inbreeding depression in benign and stressful environments. Heredity, 95, 235-242.

Aviles, L., \& Bukowski, T. C. (2006). Group living and inbreeding depression in a subsocial spider. Proceedings of the Royal Society B-Biological Sciences, 273, 157-163. Baruffaldi, L., Costa, F. G., Rodriguez, A., \& Gonzalez, A. (2010). Chemical communication in Schizocosa malitiosa: evidence of a female contact sex pheromone and 
persistence in the field. Journal of Chemical Ecology, 36, 759-767.

Bateson, P. (1982). Preferences for cousins in Japanese Quail. Nature, 295, 236-237.

Bayne, K., \& Wang, J. (2014). Oversight of Animal Research in China. In J. Guillén (Ed.), Laboratory Animals (pp. 243-266). Boston: Academic Press.

Bilde, T., Maklakov, A. A., Meisner, K., la Guardia, L., \& Friberg, U. (2009). Sex differences in the genetic architecture of lifespan in a seed beetle: extreme inbreeding extends male lifespan. BMC Evolutionary Biology, 9, 33.

Bretman, A., Wedell, N., \& Tregenza, T. (2004). Molecular evidence of postcopulatory inbreeding avoidance in the field cricket Gryllus bimaculatus. Proceedings of the Royal Society B-Biological Sciences, 271, 159-164.

Charlesworth, D., \& Charlesworth, B. (1987). Inbreeding depression and its evolutionary consequences. Annual Review of Ecology and Systematics, 18, 237-268.

Chuine, A., Sauzet, S., Debias, F., \& Desouhant, E. (2015). Consequences of genetic incompatibility on fitness and mate choice: the male point of view. Biological Journal of the Linnean Society, 114, 279-286.

Cornell, S. J., \& Tregenza, T. (2007). A new theory for the evolution of polyandry as a means of inbreeding avoidance. Proceedings of the Royal Society B-Biological Sciences, 274, 2873-2879.

Costa, F. G., Curbelo, B., \& Perez-Miles, F. (2015). Long-term persistence and water resistance of female sex cues in the tarantula Eupalaestrus weijenberghi (Araneae: Theraphosidae). Arachnology, 16, 311-313. Dougherty, L. R., \& Shuker, D. M. (2015). The effect of experimental design on the 
measurement of mate choice: a meta-analysis. Behavioral Ecology, 26, 311-319.

Duthie, A. B., Lee, A. M., \& Reid, J. M. (2016). Inbreeding parents should invest more resources in fewer offspring. Proceedings of the Royal Society B-Biological Sciences, $283,20161845$.

Escobar, J. S., Auld, J. R., Correa, A. C., Alonso, J. M., Bony, Y. K., Coutellec, M. A., Koene, J. M. Pointier, J. P., Jarne, P., \& David, P. (2011). Patterns of mating-system evolution in hermaphroditic animals: correlations among selfing rate, inbreeding depression, and the timing of reproduction. Evolution, 65, 1233-1253.

Firman, R. C., \& Simmons, L. W. (2008). Polyandry facilitates postcopulatory inbreeding avoidance in house mice. Evolution, 62, 603-611.

Fischer, K., Karl, I., Heuskin, S., Janowitz, S., \& Dotterl, S. (2015). Kin recognition and inbreeding avoidance in a butterfly. Ethology, 121, 977-984.

Fitzpatrick, J. L., \& Evans, J. P. (2014). Postcopulatory inbreeding avoidance in guppies. Journal of Evolutionary Biology, 27, 2585-2594.

Fox, C. W., \& Reed, D. H. (2011). Inbreeding depression increases with environmental stress: an experimental study and meta-analysis. Evolution, 65, 246-258.

Fox, C. W., Stillwell, R. C., Wallin, W. G., Curtis, C. L., \& Reed, D. H. (2011).

Inbreeding-environment interactions for fitness: complex relationships between inbreeding depression and temperature stress in a seed-feeding beetle. Evolutionary Ecology, 25, 25-43.

Fox, J., \& Weisberg, S. (2011). An $\{R\}$ Companion to Applied Regression (2nd ed.). Thousand Oaks CA: Sage Publishing.

Freitak, D., Bos, N., Stucki, D., \& Sundstrom, L. (2014). Inbreeding-related trade-offs 
in stress resistance in the ant Formica exsecta. Biology Letters, 10, 20140805. Gaskett, A. C. (2007). Spider sex pheromones: emission, reception, structures, and functions. Biological Reviews, 82, 26-48.

Geiselhardt, S., Otte, T., \& Hilker, M. (2009). The role of cuticular hydrocarbons in male mating behavior of the mustard leaf beetle, Phaedon cochleariae (F.). Journal of Chemical Ecology, 35, 1162-1171.

Gershman, S. N., Barnett, C. A., Pettinger, A. M., Weddle, C. B., Hunt, J., \& Sakaluk, S. K. (2010). Inbred decorated crickets exhibit higher measures of macroparasitic immunity than outbred individuals. Heredity, 105, 282-289.

Hedrick, P. W., \& Garcia-Dorado, A. (2016). Understanding inbreeding depression, purging, and genetic rescue. Trends in Ecology \& Evolution, 31, 940-952.

Herzner, G., Schmitt, T., Heckel, F., Schreier, P., \& Strohm, E. (2006). Brothers smell similar: variation in the sex pheromone of male European Beewolves Philanthus triangulum F. (Hymenoptera : Crabronidae) and its implications for inbreeding avoidance. Biological Journal of the Linnean Society, 89, 433-442.

Hosken, D. J., Stockley, P., Tregenza, T., \& Wedell, N. (2009). Monogamy and the battle of the sexes. Annual Review of Entomology, 54, 361-378.

Jiao, X. G., Chen, Z. Q., Wu, J., Du, H. Y., Liu, F. X., Chen, J. A., \& Li, D. Q. (2011). Male remating and female fitness in the wolf spider Pardosa astrigera: the role of male mating history. Behavioral Ecology and Sociobiology, 65, 325-332.

Keane, B. (1990). Dispersal and inbreeding avoidance in the white-footed mouse, Peromyscus leucopus. Animal Behaviour, 40, 143-152. 

temperatures increase the deleterious consequences of inbreeding under laboratory and seminatural conditions. Proceedings of the Royal Society B-Biological Sciences, 275, 2055-2061. inclusive fitness by avoiding mating with kin. Animal Behaviour, 80, 303-309. Lynch, M. (1991). The genetic interpretation of inbreeding depression and outbreeding depression. Evolution, 45, 622-629. nonsiblings on the reproductive success in a leaf beetle. Ecology and Evolution, 6, 31853197.

Sciences, 283, 20161023.

Evolution, 11, 201-206. 1505.

R Development Core Team. (2017). R: A language and environment for statistical computing. Vienna, Austria: R Foundation for Statistical Computing. Retrieved from 
level of inbreeding in the common lizard. Proceedings of the Royal Society B-Biological Sciences, 276, 2779-2786.

Roberts, J. A., \& Uetz, G. W. (2004). Chemical signaling in a wolf spider: a test of ethospecies discrimination. Journal of Chemical Ecology, 30, 1271-1284.

Ruch, J., Heinrich, L., Bilde, T., \& Schneider, J. M. (2009). The evolution of social inbreeding mating systems in spiders: limited male mating dispersal and lack of precopulatory inbreeding avoidance in a subsocial predecessor. Biological Journal of the Linnean Society, 98, 851-859.

Sherman, C. D. H., Wapstra, E., Uller, T., \& Olsson, M. (2008). Males with high genetic similarity to females sire more offspring in sperm competition in Peron's tree frog Litoria peronii. Proceedings of the Royal Society B-Biological Sciences, 275, 971-978. Simmons, L. W., Beveridge, M., Wedell, N., \& Tregenza, T. (2006). Postcopulatory inbreeding avoidance by female crickets only revealed by molecular markers. Molecular Ecology, 15, 3817-3824.

Smith, D. R., Su, Y. C., Berger-Tal, R., \& Lubin, Y. (2016). Population genetic evidence for sex-specific dispersal in an inbred social spider. Ecology and Evolution, 6, 54795490.

Szulkin, M., Stopher, K. V., Pemberton, J. M., \& Reid, J. M. (2013). Inbreeding avoidance, tolerance, or preference in animals? Trends in Ecology \& Evolution, 28, 205-211. Thomas, M. L., \& Simmons, L. W. (2011). Crickets detect the genetic similarity of mating partners via cuticular hydrocarbons. Journal of Evolutionary Biology, 24, 1793-1800. Tregenza, T., \& Wedell, N. (2002). Polyandrous females avoid costs of inbreeding. 
Nature, $415,71-73$.

Valtonen, T. M., Roff, D. A., \& Rantala, M. J. (2011). Analysis of the effects of inbreeding on lifespan and starvation resistance in Drosophila melanogaster. Genetica, 139, $525-533$.

Venables, W. N., \& Ripley, B. D. (2002). Modern Applied Statistics with S (4th ed.).

New York: Springer.

Welke, K., \& Schneider, J. M. (2009). Inbreeding avoidance through cryptic female choice in the cannibalistic orb-web spider Argiope lobata. Behavioral Ecology, 20, 10561062.

Whitehorn, P. R., Tinsley, M. C., \& Goulson, D. (2009). Kin recognition and inbreeding reluctance in bumblebees. Apidologie, 40, 627-633.

Wilder, S. M. (2011). Spider nutrition: an integrative perspective. Advances in Insect Physiology, 40, 87-136.

Wise, D. H. (2006). Cannibalism, food limitation, intraspecific competition, and the regulation of spider populations. Annual Review of Entomology, 51, 441-465.

Wu, J., Jiao, X. G., \& Chen, J. (2008). Courtship and mating behaviors of the wolf spider Pardosa astrigera. Chinese Journal of Zoology, 43, 9-12.

Xiao, R., Chen, B., Wang, Y. C., Lu, M., Chen, J., Li, D. Q., Yun, Y.L., \& Jiao, X. G. (2015). Silk-mediated male courtship effort in the monandrous wolf spider Pardosa astrigera (Araneae: Lycosidae). Chemoecology, 25, 285-292. 


\section{Figure Legends}

459

Figure 1. Male courtship behaviors in response to sibling versus non-sibling females.

460 Panels A-D: courtship in the presence of silkborne cues produced by sibling (filled bars) and

461 non-sibling (open bars) females. Panels E-H: courtship in the physical presence of sibling and

462 non-sibling females.

463 Figure 2. Female reproduction (A-B) and fecundity (C-D) following mating with

464 sibling (filled bars) and non-sibling (open bars) males.

465

Figure 3. Survival of offspring (days) from sibling-mated females (filled circles) and

466

non-sibling mated females (open triangles) held without food or water at 15,25 , and $30{ }^{\circ} \mathrm{C}$. 
Figure 1.
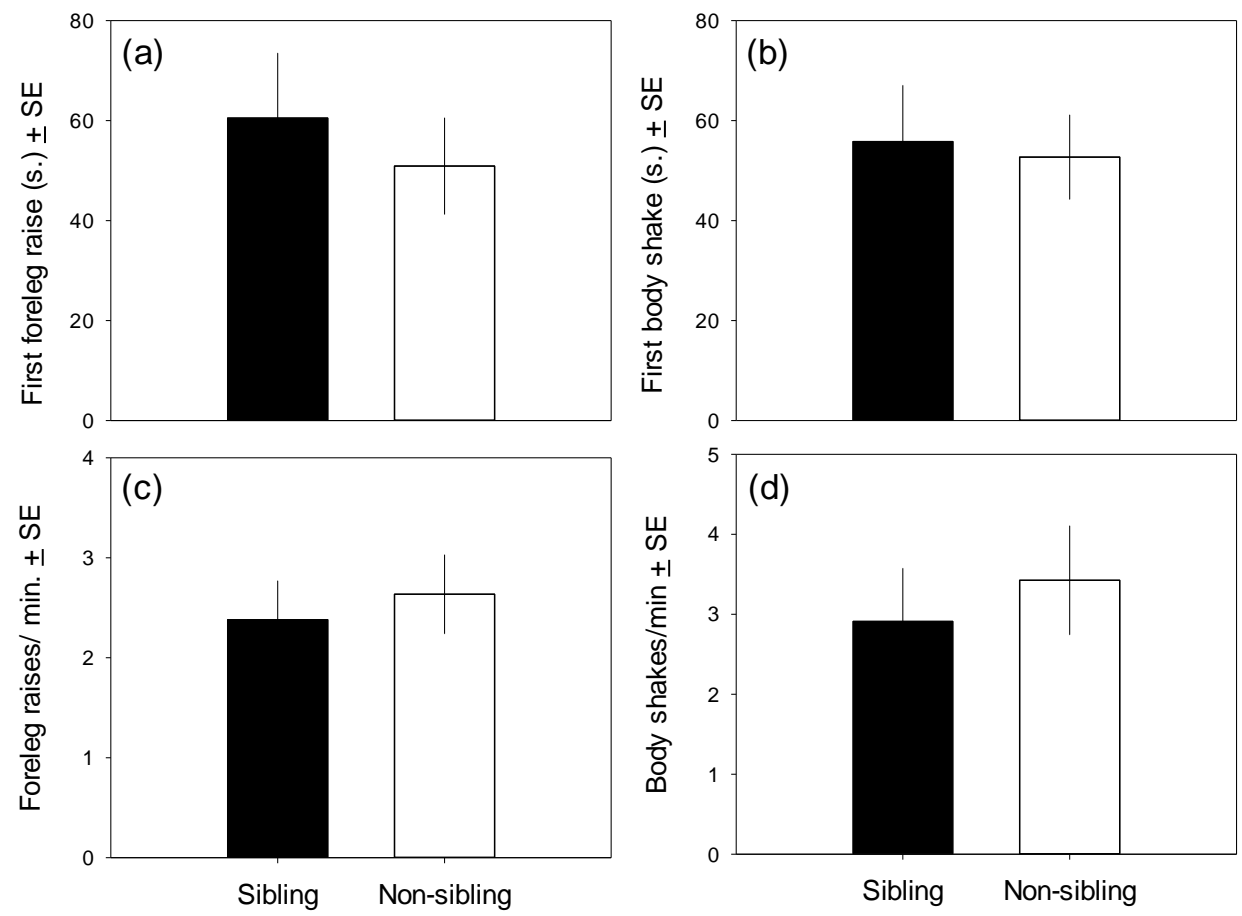

Male response to female silk cues (experiment 1)
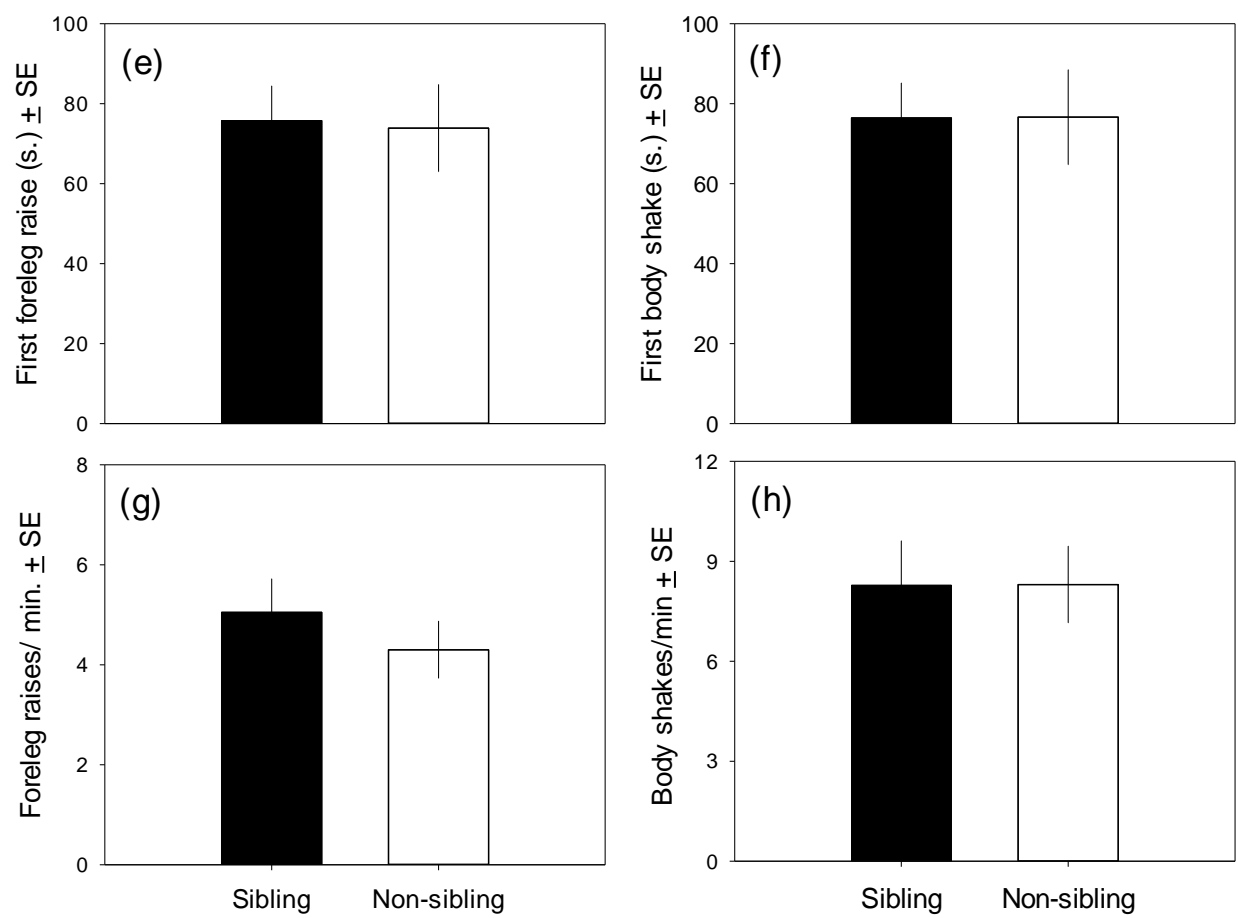

Male response to female (experiment 2) 
Figure 2.
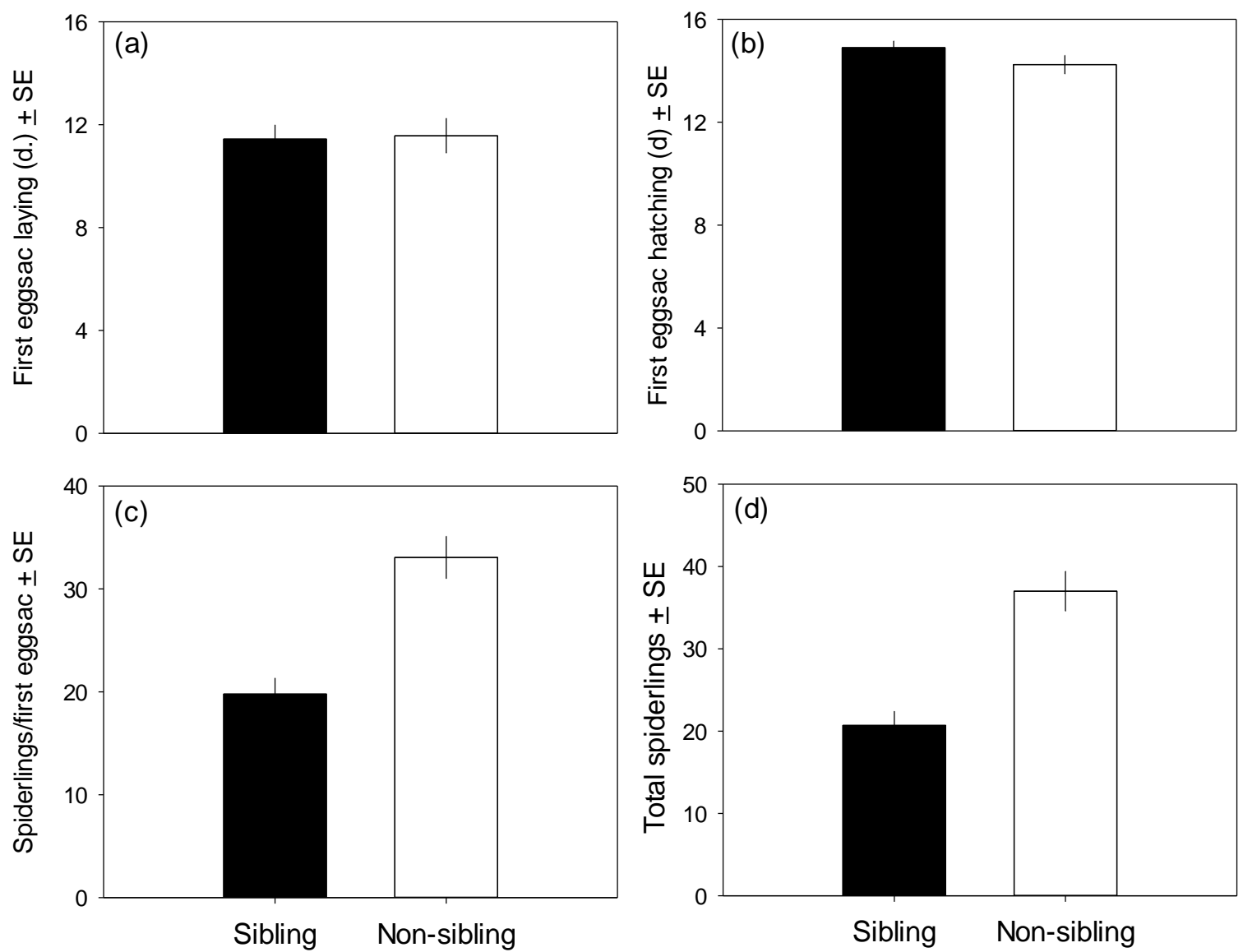

Result of male-female pairing

471 
473 Figure 3.

474

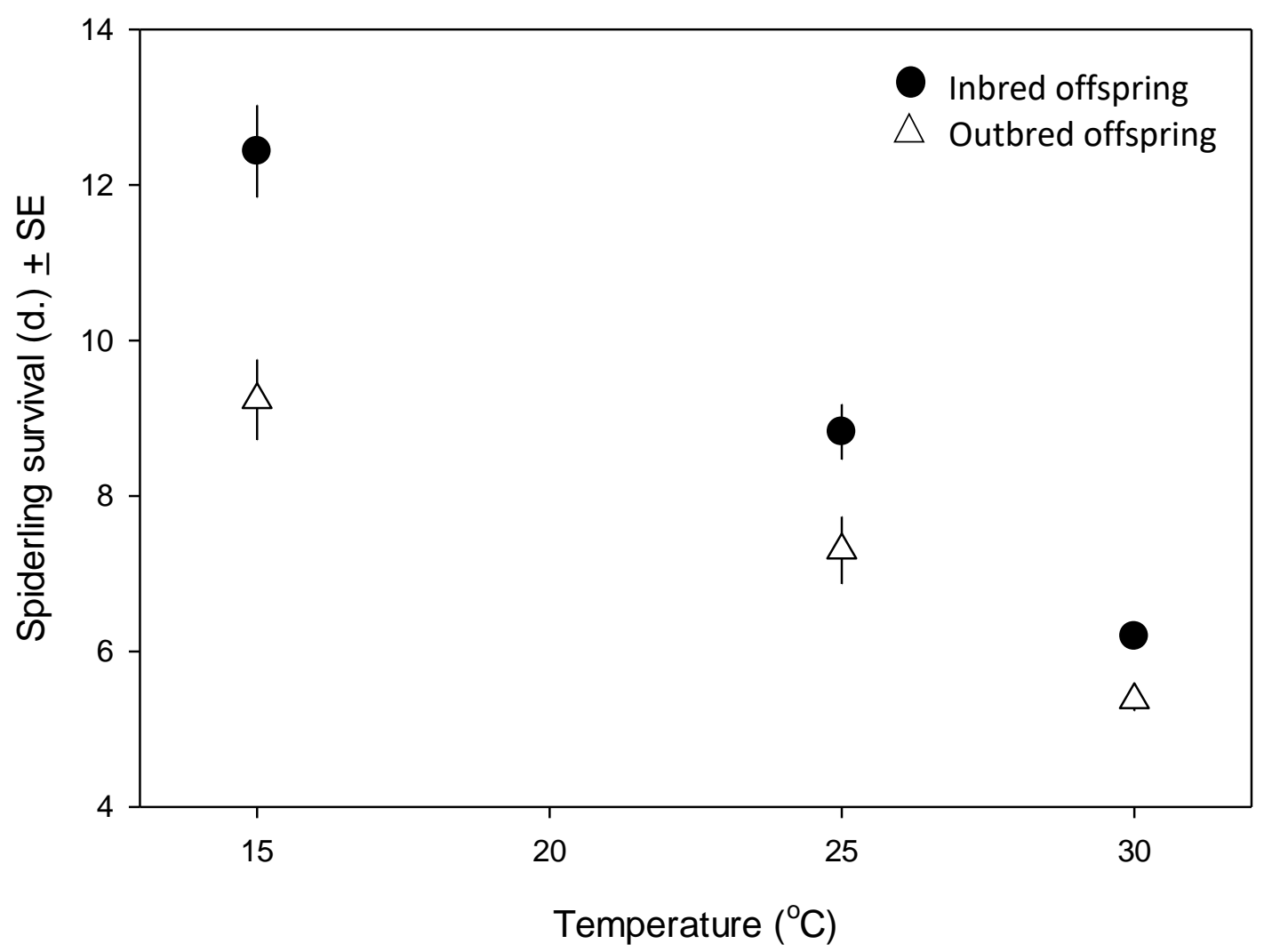

